\title{
The Research of Extracting Soluble Sylvite from Breeding Wastewater
}

\author{
Yu Guo ${ }^{1, a}$ \\ ${ }^{1}$ School of chemistry and chemical engineering, Guizhou University, Guiyang, China, 550025 \\ agy1988@yeah.net
}

Keywords: Soluble Sylvite, Breeding wastewater, Extraction, Zeolite

Abstract. The experiment selected zeolite from ten absorption agent to adsorb potassium. Through the investigated of amount of zeolite, adsorption time and temperature, found the best parameters. When zeolite was used with $2 \mathrm{~g}$, adsorption time was $60 \mathrm{~min}$ and temperature was $20^{\circ} \mathrm{C}$, the extraction rate was $66.67 \%$. The result show that zeolite can be reused.

\section{Introduction}

With rapid development of poultry industry, animal manures have become a major pollution to our environment. In 2003, nationwide animal manure reached 3.190 billion t, which is 3.2 times of industrial solid waste in the same term [1]. In 2009, nationwide animal manure achieved 3.264 billion t, 1.6 times of industrial solid waste in the same term [2]. It is estimated that the amount would be as high as 4.244 billion $t$ in 2020[3]. When the amount of livestock and poultry is grown, the influence is bigger, such as the waste water from the farm with many contamination could pollutes badly the clear water and cropland if waste water was push out direct without suitably management[4-8]. In the end, this is no more clear water for living and the cropland for food. Because of the grim situation, more and more researchers work for a suitable way to solve the waste water containing high COD and soluble sylvite which can be an important potassium resource for our country. As the shortage of the potash resource in china [9-12], many researchers work for extracting potassium from bittern and seawater [13-14]. By the reports, main technology of extracting potassium contains brine mixing method, chemical precipitation method, solvent extraction technology, separation membrane and ion exchange process, and the best extraction method from low potassium solution is ion exchange process. There are many reports about selecting and preparing the suitable potassium-adsorbing dosage [14-17], as ion exchange resin, inorganic ion exchanger, zeolite and so on. As the bittern or seawater, the breeding wastewater contains some soluble sylvite too. Depending on most of animals making manure and urine at same time, it can be estimated that the amount of breeding wastewater would be more than 4.244 billion stere in 2020 . If the content of the potassium in the wastewater can reach $3 \sim 4 \mathrm{~g} / \mathrm{L}$, the amount of potassium (calculated by the $\mathrm{K}_{2} \mathrm{O}$ ) in breeding wastewater would be $13 \sim 17$ kilo $\mathrm{t}$ in 2020 . As the report, the amount of potash fertilizer would be 3800 kilo $t$ in 2020, so the amount of potassium in the wastewater can reach 3 4\% in potash fertilizer. Because the breeding wastewater is regenerate every year, if the part of potassium in the wastewater can be used, it can be an important substitute for preparing potash fertilizer.

In this paper, potassium-adsorbing dosage focused on the enrichment and extraction the soluble sylvite from cattle urine is research, and the best extraction condition is studied too.

\section{Experimental Section}

Extraction by liquid emulsion membrane

Put an adsorbing dosage into a $250 \mathrm{ml}$ taper bottle, and rejoin some breeding wastewater containing soluble sylvite and keeping the temperature at a certain degree about 30 240 min. During this time, the taper bottle must be put into a thermostatic shaker. When the adsorbing is completed, put some clear liquid from the top of the taper bottle, and test the absorption ratio by the flame absorption spectrophotometric method. 
Selection adsorbing dosage

Weigh separately zeolite, active carbon, kaoline, infusorial earth, silica gel, active alumina, ash of cattle dung, coal fly ash, bamboo leaf ash and slag each $1 \mathrm{~g}$, put separately these absorptions into a taper bottle, follow above method to test the adsorbing ability of these materials.

Desorption of potassium from absorption dosage

Put some absorption dosage into a $250 \mathrm{ml}$ taper bottle, and rejoin some desorption agent in the taper bottle, and keeping the room temperature about 60min. During this time, the taper bottle must be put into a thermostatic shaker. When the desorbing is completed, put some clear liquid from the top of the taper bottle, and test desorption ratio by the flame absorption spectrophotometric method and spectrophotometric method.

\section{Results and Discussion}

In the Table1, the extraction efficiency of ten different adsorbing dosages to extract same concen -tration potassium under same condition, the condition is putting $1 \mathrm{~g}$ adsorbing agent into $25 \mathrm{ml}$ urine and keep them at $25^{\circ} \mathrm{C}$ about $24 \mathrm{~h}$, is searched. As the data shown, during these absorbing dosages, the zeolite played the best ability, but other dosages can't absorb potassium well. So the suitable dosage for adsorbing potassium from urine is zeolite, other dosages couldn't be used straightly as adsorbing dosage unless these dosages could be modified.

Table 1 Extraction efficiency of ten different adsorbing dosages

\begin{tabular}{cccccc}
\hline Absorbing dosage & zeolite & active carbon & kaoline & infusorial earth & active alumina \\
\hline Extraction $(\%)$ & 52.22 & 12.17 & 9.12 & 5.23 & 4.05 \\
\hline Absorbing dosage & ash of cattle dung & coal fly ash & bamboo leaf ash & slag & silica gel \\
\hline Extraction $(\%)$ & 2.12 & 1.09 & 0.22 & 1.23 & 1.98 \\
\hline
\end{tabular}

As the zeolite been chosen out, how to absorb most efficiently the potassium from urine is research. In the investigation, the amount of zeolite, adsorption time and temperature had been studied, and the answer is shown by Fig. $1 \sim$ Fig.3.

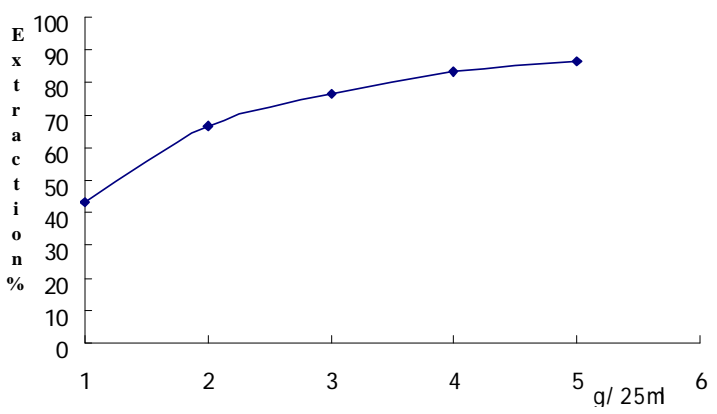

Fig.1 The effect of dosage of zeolite on extraction efficiency

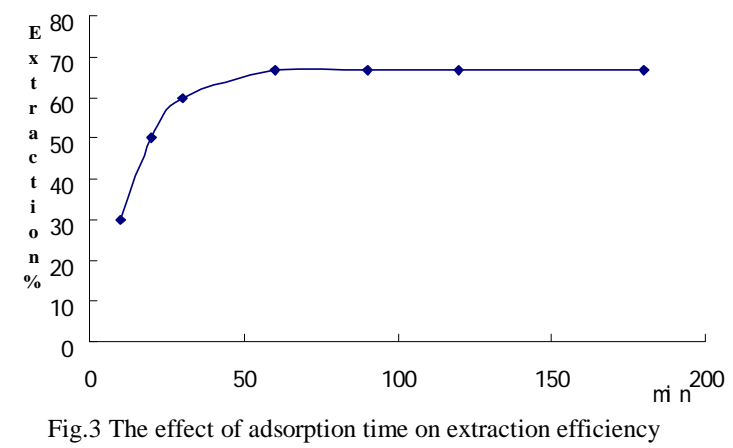

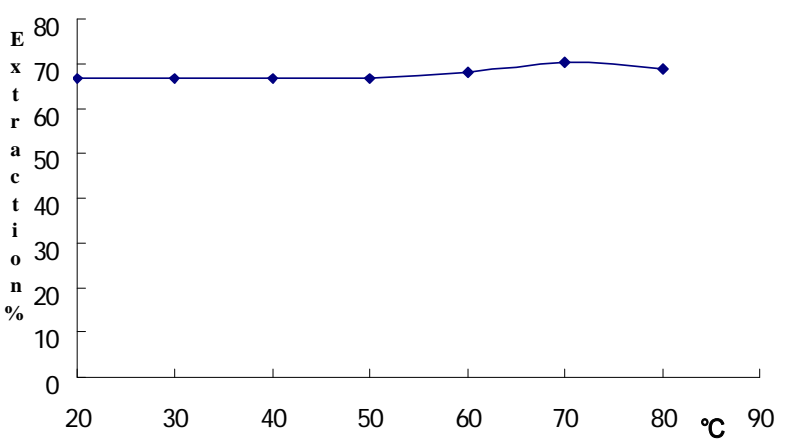

Fig. 2 The effect of adsorption temperature on extraction efficiency

From the Fig.1, it is clear that the extraction increases with the adding dosage of zeolite. When the amount of zeolite reaches $5 \mathrm{~g} / 25 \mathrm{ml}$ (urine), the extraction can be $86.67 \%$, but the increase rate becomes slower when the dosage of the zeolite is more then $2 \mathrm{~g} / 25 \mathrm{ml}$. So depending on the efficiency of per gram zeolite in $25 \mathrm{ml}$ urine and the cost, using the zeolite $2 \mathrm{~g} / 25 \mathrm{ml}$ is a suitable choice. In the Fig.2, we can see the effect of the experiment

temperature on the extraction. With the change of the temperature, the extraction almost keeps at 
$66.67 \%$, when the temperature increases to $70^{\circ} \mathrm{C}$, the extraction reaches $70.40 \%$, but the adding with temperature is not obvious, so the change of the temperature can't affected evidently the extraction, and the room temperature is already suitable for extracting potassium from urine. When the extraction time is different, the ratio of extraction is different too, so finding right time for our research is important. The seven experiments had been designed with seven times from 10min to 180min; the results had been shown at Fig.3. As the data of Fig.3, the clear trend is the higher extraction ratio with longer reaction time, but when the reaction time is over $60 \mathrm{~min}$, the ratio keeps straightly at $66.67 \%$, so the reaction time is between $30 \mathrm{~min}$ and $60 \mathrm{~min}$, considering the equilibration time, the extraction time should be $60 \mathrm{~min}$. Through the several series of experiments, the best parameters is using zeolite with $2 \mathrm{~g} / 25 \mathrm{ml}$, adsorption time $60 \mathrm{~min}$ and room temperature, and the extraction rate can reach $66.67 \%$.

The urine contains some potassium and others, as nitrogenous compounds, phosphorated compounds. They could be absorbed by the zeolite too. These compounds would affect the extraction of potassium or not, it had been studied and the result is listed at Table 2 . We can see that the nitrogenous compounds and phosphorated compounds had been absorbed by zeolite too, but they didn't cut down the ratio of potassium extraction, the ratio is even higher than $66.67 \%$, which could be the higher content of potassium in urine, and the nitrogenous and phosphorated compounds would help the absorption by $\mathrm{N}$ and $\mathrm{P}$ atom with rich electron.

Table 2 The effect of other compounds in urine on extraction efficiency of potassium

\begin{tabular}{cccc}
\hline Condition & Potassium $(\mathrm{g} / \mathrm{L})$ & Nitrogen $(\mathrm{g} / \mathrm{L})$ & Phosphorus $(\mathrm{mg} / \mathrm{L})$ \\
\hline Before extraction & 5.81 & 9.41 & 38.8 \\
After extraction & 1.70 & 7.59 & 32.64 \\
\hline Extraction ratio(\%) & 70.74 & 19.34 & 15.88
\end{tabular}

Absorbed potassium should be desorbed from zeolite, the condition of desorbed potassium had been investigated too. There are three kinds of desorption agents designed for finding the suitable way, the result is shown at Table 3 .

Table 3 The choice of desorption agents

\begin{tabular}{cccc}
\hline Desorption agent & Dilute sulphuric acid & Diluted phosphoric acid & Saturated ammonium chloride \\
\hline $\begin{array}{c}\text { Desorption ratio of } \\
\text { Potassium(\%) }\end{array}$ & 90.75 & --- & 94.45 \\
\hline $\begin{array}{c}\text { Desorption ratio of } \\
\text { Nitrogen (\%) }\end{array}$ & 45.60 & --- & --- \\
\hline $\begin{array}{c}\text { Desorption ratio of } \\
\text { Phosphorus }(\%)\end{array}$ & 35.71 & --- & --- \\
\hline
\end{tabular}

As the Table 3 shown, the saturated ammonium chloride is the best desorption agent for the zeol ite, but the zeolite had absorbed some nitrogenous compounds from urine. Desorbing potassium from zeolite in saturated ammonium chloride would affect the desorbing of nitrogenous compounds, so th e saturated ammonium chloride is a good choice. From the table 3, desorption ratio in diluted phosph oric acid can't be tested, and the reason is that zeolite could be dissolved in the diluted phosphoric aci d. So the desorption agent should be the dilute sulphuric acid, using this desorption agent $90.75 \%$ pot assium, $45.60 \%$ nitrogen and $35.71 \%$ phosphorus could be desorbed. Zeolite is used only once as the absorption agent, the cost of absorption is too high, so the reuse of zeolite should be researched and shown the data in Table 4.

Table 4 The choice of desorption agents

\begin{tabular}{ccccccc}
\hline Use times & First & Second & Third & Fourth & Fifth & Sixth \\
\hline Extraction ratio(\%) & 66.67 & 64.22 & 60.07 & $61.79 \%$ & 60.23 & 62.01 \\
\hline
\end{tabular}

When the zeolite is desorbed by diluted phosphoric acid, put the renewed zeolite to absorb the $\mathrm{p}$ otassium again, the absorption ratio decreased a little, but the ratio can keep about $60 \%$, so using the zeolite absorbing potassium from urine is feasible way to recycle soluble sylvite from urine. 


\section{Conclusions}

In this paper, the soluble sylvite extracting from breeding wastewater is studied. For improving the searching extraction efficiency, lots of influence factors were searched, such as what and how much absorption agents are suitable, how much temperature and time of absorption, and how to efficiently desorb. As the outcome shown, the experiment selected zeolite to adsorpt potassium. Through the investigated of amount of zeolite, adsorption time and temperature, found the best parameters. When zeolite was used with $2 \mathrm{~g}$, adsorption time was $60 \mathrm{~min}$ and temperature was $20^{\circ} \mathrm{C}$, the extraction rate was $66.67 \%$, and the others compounds in the urine as nitrogenous and phosphorated compounds played a favorable role for improving the extraction of the absorbing potassium. Finally, the desorption condition had been studied too, the diluted phosphoric acid is a good desorption agent for zeolite, and the desorption ratio can reach $90.75 \%$, others compounds can desorded too, so the compound fertilizer could be made by zeolite absorbing from urine, and the zeolite can be reused several times, which means that the zeolite absorbing potassium from urine is feasible way.

\section{Acknowledgements}

This work was financially supported by the Guizhou Science and Technology Foundation (QianKeHe J Zhi(2009)2018 Hao) and the Guizhou Social Development Foundation (QianKeHe sy Zhi (2011)3127 Hao).

\section{References}

[1]F. H. Wang, W. Q. Ma:China Environmental Science, Vol 26(5)(2006) P.614-617(In Chinese). [2] Tian Zhang, Meidou Bu, Wei Geng: Chinese Journal of Ecology, Vol 31(5)(2012) P.1241-1249(In Chinese).

[3] Fenglian Zhu, Youhua Ma, Jing Zhou: Anhui Agricultural Science Bulletin, Vol 14(13) (2008) P.48-50(In Chinese).

[4] Chuanjie Jiang, Yan Wang, Yuxia Zhang: Henan Journal of Husbandry and Veterinary Medicine, Vol 26(1) (2005) P.28-31(In Chinese).

[5] Shutian Li, Rongle Liu, Hong Shan: Journal of Agro-Environment Science, Vol 28 (1) (2009) P. 179-184(In Chinese)

[6] Qingkang Li, Lei Wu, Haiqing Liu: Agro-Environmental Protection, Vol 19(4) (2000) P.251-254 (In Chinese).

[7] Xiaoguang Li, Qiwen Zhou, Mei Hu: Environmental Contamination Chinese Agricultural Science Bulletin, Vol 24 (2008) P. 77-80(In Chinese)

[8] Wei Ding, Hehua Er, Tianxin Wang:Ningxia Journal of Agriculture and Forestry Science and Technology, Vol 2 ( 2009) P. 54-56(In Chinese).

[9] Jiaming Wang: Chemical Enterprise Management, Vol 9 (2009) P.17-23(In Chinese). .

[10] Fengqing Xu : Modern Agricultural Science and Technology, Vol 12( 12) (2010) P. 252-253(In Chinese) .

[11] Hongwen Ma, Shuangqing Su, Hao Liu, Xue Yang, Hui Peng, Zijian Yu: Earth Science Frontiers, Vol 17( 1) (2010) P.294-310(In Chinese).

[12] H. W. Ma: Potassic Rock s in China: Resource and Clean Utilization Techniques (Chemical Industry Press, Beijing 2010).

[13] Changhong Li, Minghai Li: Journal of Salt Lake Research, Vol 18(1) (2010) P. 64-66 (In Chinese).

[14] Wenyuan Gao, Ru Wang, Longqin Zhou: Chemical Research and Application, Vol 21(2) (2009) P. 239-242 (In Chinese).

[15] Li Wang, Jianjun Yuan: China Mining Magazine, Vol 17(1) (2008) P. 84-88 (In Chinese).

[16] P. Y. Feng, X.H.Bu, SHTolbext, GDStucky: J .Am .Chem. Soc ,Vol 119(10) (1997)P.2497-2504 
[17] WagnerP, YoshikawaMLovaHoM,TsujiK ,TaspatsisM ,DavisME: Chem .Comrnun, Vol22 (1997) P. 2179-2180. 